\title{
On the Cover
}

Portions of the following are based on an interview with the artist on June 6, 2011.

How does one represent 9/11-the hugeness of the event, the moments of that day, let alone its impact over time? No doubt, for each reader of this journal, there are associations, stories, meanings, and projections. Tragedy and resilience, loss and recovery; transience and permanence, the momentary and the steadfast; serendipity juxtaposed with intention. This month's cover art symbolizes these complex affective experiences.

Artist Becky Strube is a polymath: An architectural designer by profession, she is also a lyricist, poet, arts and community advocate, choral singer, wife, and mother. Strube and her husband, well-known Latvian-Canadian composer Imant Raminsh, have lived and practiced in the Okanagan Valley of British Columbia since 1978.

A dual citizen of the United States and Canada, Strube was born and raised in Jackson, Minnesota. "My spatial concepts, color sense, and joy of exploring possibilities were developed at a young age. My father owned a construction business. He had four daughters and one sonand was color blind. He would buy up old houses, and we would have to redesign and remodel them." Strube studied liberal arts and international relations at the University of Minnesota and visual arts in Canada at the Banff School of Fine Arts, before graduating with a degree in architectural design.

About her artistic endeavors, Strube comments, "I've come to embrace the Japanese concept of wabi-sabi - the art of imperfection-in all my artistic endeavors. I prefer to treat all as a growing-learning process and not an end in itself. I'm at the stage where I love to free up my inhibitions with the fluidity of letting go." She says that this was the perfect attitude to bring to the artists' retreat/workshop in 2004 during which she painted Crucible of Chaos, this month's cover art.

At that retreat, each artist was given five different jars of paint, a $9 \times 12$ inch piece of paper canvas, a time limit, and no further instruction. Strube received black, various metallic paints (gold, copper, and green), and a paint product called interference violet. This product contains coated mica particles that appear iridescent in some angles of light. Crucible of Chaos was the result of that liberating exercise in creating on impulse. "I had to act, I couldn't just stand there and think about it. I had to create, to rise above my limitations."
A number of close relatives had died shortly before this workshop, and Strube feels this painting came out of her own experience of grief: "A crucible was traditionally a vessel for refining impurities in metal to create something pure, as in gold. In this painting, the crucible is on its side, spilling these pure contents over the darker background aspects. I think it is a good metaphor for living in our complex world."

Strube comments that the combination of the dark background swaths and the gold sweeps in some ways purifies and makes precious the light rising above the dark. A crucible, or test by fire, is juxtaposed with chaos, which Strube defines as "a state of things in which chance is supreme and nature is subject to no law." Drawing parallels between her personal experience and that of September 11, 2001, Strube reflects, "Grief becomes our own trial by fire. One never forgets, but our better nature triumphs, and in forging something new we rise above the pain."

The editorial team for American Psychologist searched broadly for an image that would be appropriate for this issue of the journal; the intention was to choose a painting that would be experienced in a number of ways, as befit the occasion, our readers' varied experiences, and the wide range of article topics. It is perhaps apt for this essay to conclude with a personal connection. After all, we each recall our own experiences of September 11, 2001, and we each know the paths we have subsequently taken.

I am a member of Orpheus Choir of Toronto. In the spring of 2011 we were preparing to sing a composition by Raminsh with Strube's poetry for the libretto. The composition, titled Quaternity, A Cantata for Seasons, references "the yearly natural cycles of birth, flowering, ripening, decay, and rebirth ... in general, the inevitable stages of each person's life."

As I studied my copy of the musical score, the painting on the cover intrigued me. I had no idea who the artist was, yet the sheer energy, power, and movement of the image drew my eye in. Strube was the artist, and Crucible of Chaos, the painting. In Quaternity, Strube writes,

All wild paths meandering sing this untamed aria to now being free, alive, this unrepeated ... day.

Kate F. Hays Art Co-Editor 